\title{
Evolution of Dislocation Substructures in Fatigue Loaded and Failed Stainless Steel Processed by High-intensity Electron Beam
}

\author{
S.V. Konovalov ${ }^{1}$, S.V. Vorobyev $^{1}$, Yu.F. Ivanov $^{2}$, S.V. Gorbunov ${ }^{1}$, V.I. Myasnikova ${ }^{1}$, V.E. Gromov ${ }^{1, *}$ \\ ${ }^{1}$ Department of physics, State Siberian Industrial University, Novokuznetsk, 654007, Russia \\ ${ }^{2}$ Institute of High Current Electronics, Siberian Division of the Russian Academy of Sciences, Tomsk, 634055, Russia
}

\begin{abstract}
Electron-beam treatment of $08 \mathrm{Cr} 18 \mathrm{Ni10Ti}$ steel in the mode of $\sim 5 \mu \mathrm{m}$ surface layer melting (electron beam energy density is $25 \mathrm{~J} / \mathrm{cm}^{2}$ ) results in increase in fatigue durability by a factor of 3.44. Investigations of the structure-phase states and defective substructure and the factors responsible for increase in fatigue durability of steel have been carried out by the methods of optical, scanning and transmission electron diffraction microscopy.
\end{abstract}

Keywords Electron-Beam Treatment, Fatigue, Defective Substructure

\section{Introduction}

Physical nature and behaviour pattern of steels and alloys under cyclic loading remain insufficiently investigated because a whole set of factors (phase structure, defective substructure, surface layer state, medium and temperature of tests, frequency and amplitude of operating loading, etc.) has an impact on the fatigue failures[1, 2]. Increase of fatigue durability of a stainless steel and, accordingly, safe terms of products operation can be achieved by pulse current processing[3-5].

Since fatigue failure begins mainly from the surface layer then its hardening makes possible the increase of fatigue characteristics[6]. The purpose of the present work is to analyse the laws of structure-phase transformation of the surface layer of $08 \mathrm{Cr} 18 \mathrm{Ni} 10 \mathrm{Ti}$ steel, processed by the electron-beam within sub millisecond time range and destroyed as a result of multicyclic fatigue tests.

\section{Material and investigation methods}

Stainless steel 08Cr18Ni10Ti (0.08 wt. \% C, 18 wt. \% Cr, 10 wt. $\% \mathrm{Ni},<1 \mathrm{wt} . \% \mathrm{Ti}$ ) was chosen as the material of study. The samples were subjected to annealing at $1273 \mathrm{~K}$ (2 hours) with the subsequent cooling in water. As in[3-5] the fatigue tests were carried out with a special shaped device for cyclic asymmetric cantilever bending of samples shaped as $8 \mathrm{~mm} \times$

\footnotetext{
* Corresponding author:

gromov@physics.sibsiu.ru (V.E. Gromov)

Published online at http://journal.sapub.org/materials

Copyright $(\underset{2}{2012}$ Scientific \& Academic Publishing. All Rights Reserved
}

$15 \mathrm{~mm} \times 145 \mathrm{~mm}$ parallelepiped. Samples being in failed states after continuous loading were subjected to analysis.

Steel surface layer modification was carried out by the high-intensity electron beam with sub millisecond duration of impact $[7,8]$. The given mode of electron-beam processing corresponded to melting of $5 \mu \mathrm{m}$ thick surface layer.

Fatigue experiments were carried out on a special device according to the pattern of a cyclic asymmetrical cantilever bend. Electron beam processing resulted in cycles number increase before failure from $\mathrm{N}=1.8 \times 10^{5}$ to $\mathrm{N}=6.2 \times 10^{5}$, it shows the durability increase by the factor of 3.44 .

Investigations of steel structure-phase state were carried out by the methods of optical, scanning and transmission electron diffraction (method of thin foils) microscopy. The structure gradient investigation of steel was carried out by the analysis of foil, located at the distance of 10 and $80 \mu \mathrm{m}$ from the surface and the foils, received from the layer adjoining to the surface.

The quantitative analysis of the steel structure was carried out using methods of stereology and quantitative electronic microscopy; the phase analysis of the steel was carried out by the indexing of the micro-electron-diffraction patterns with obligatory use of dark-field techniques[9-11].

The error of a single distribution of scalar dislocation density $(\rho)$, grain volume occupied by microtwins $(\Delta \mathrm{V})$, mid-sized areas of small misorientation angle of substructur e (D), azimuthal component of the misorientation angle of substructure elements $(\Delta \alpha)$, bend extinction contours of mean density $\left(\rho_{\mathrm{K}}\right)$, bend extinction contours of mean width $(h)$, mid-sized (d) and density $(\lambda)$ of carbide particles does not exceed $10 \%$ of the measured value.

\section{Results and Discussion}




\subsection{Steel Structure Before Cycling}

Steel under investigation in its initial state (before the electron-beam processing) is a polycrystalline material with $19.6 \mu \mathrm{m}$ mid-sized grains. The intragranular structure (here after referred to as, substructure) is presented by microtwins and dislocations. In the grain the one dominant system of microtwins is observed. The average volume of the material occupied by micro twins is $\sim 0.15$. Dislocations form a reticular substructure; scalar density of dislocations is $\sim 5 \times$ $10^{10} \mathrm{~cm}^{-2}$. The phase composition of steel is characterized by presence of carbide particles of $\mathrm{M}_{23} \mathrm{C}_{6}$ type (carbide particles on the basis of chrome with composition of $(\mathrm{Cr}$, $\mathrm{Fe})_{23} \mathrm{C}_{6}$ ). The particles of globular form are distributed chaotically in the grain volume, and junction of grain boundaries. The average size of particles is $167 \mathrm{~nm}$. The particles located along the grain boundaries have the form of interlayers. In some cases the extended lines of particles (lines of dendritic segregation) are observed.

\subsection{Structure of the Near-surface Layer of Steel After Electron-Beam Processing}

Electron-beam processing of $08 \mathrm{Cr} 18 \mathrm{Ni} 10 \mathrm{Ti}$ steel in the mode mentioned above leads to the surface layer melting. High-speed steel crystallization is accompanied by structure formation of cellular crystallization, revealed by the methods of scanning and transmission electron microscopy (fig. 1).

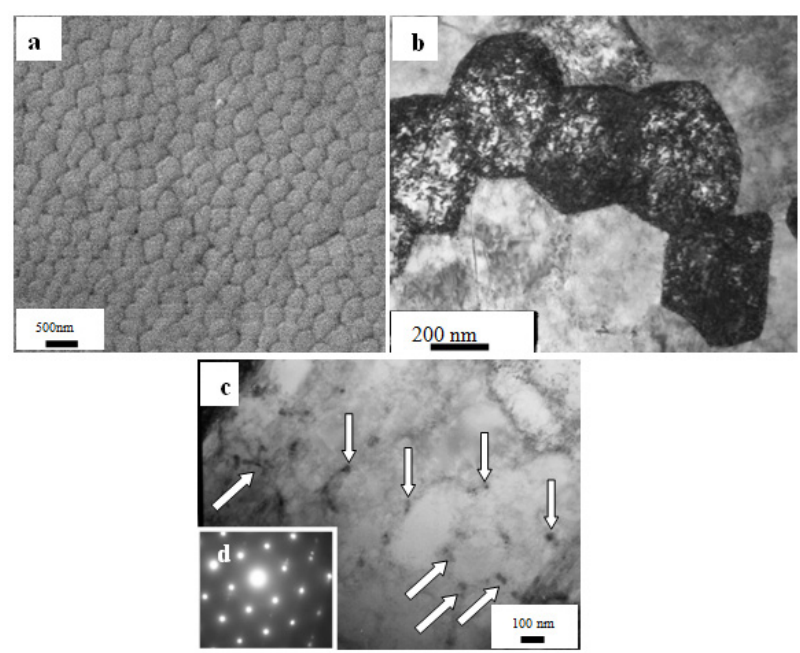

Figure 1. Structure of cellular crystallization of $08 \mathrm{Cr} 18 \mathrm{Ni} 10 \mathrm{Ti}$ steel surface after processing by an electron beam; a - scanning electronic microscopy; b-d transmission electron diffraction microscopy; b, c bright-field images; $d$ - micro-electron-diffraction pattern. In (c) arrows point at carbide particles $\mathrm{TiC}$ located on the cell boundaries

Crystallization cells have an equiaxial form with the average size of cells $\mathrm{D}=319.6 \pm 83.7 \mathrm{~nm}$. In the junctions and along the cell boundaries inclusions of the second phase, namely, titan carbide particles of the composition $\mathrm{TiC}$ and, less often, particles of $\mathrm{Cr}_{15} \mathrm{Fe}_{9}$ are located. Particles have a round form, the average sizes of particles are $18.5 \mathrm{~nm}$ (fig. 1, c). In the volume of crystallization the chaotically distributed dislocations (fig. 1, b) are found. Scalar density of dislocations is $3.6 \times 10^{10} \mathrm{~cm}^{-2}$.
The layer with the structure of cellular crystallization transits into the material volume with grains of micron sizes. In the grain volume the microtwins of a deformation origin and the dislocation substructure in the form of chaos and nets are found.

The surface processing results in formation of a gradient structure in the material, i.e. the structure with parameters that change naturally according to the distance increase from the processed surface. It is possible to conclude that electron-beam processing facilitates the surface layer hardening (the layer thickness is $\sim 10 \mu \mathrm{m}$ ) of $08 \mathrm{Cr} 18 \mathrm{Ni10Ti}$ steel. It results from the reduction in grain size, increase in scalar dislocation density and the grain volume occupied by microtwins, decrease in the size and misorientation angle increase of substructure areas, decrease in average width of a bend extinction contour. Besides, it is necessary to note the substantional (by a factor of $\sim 2.5$ ) density reduction of bend extinction contour that proves the decrease in density of stress concentrators in the surface layer.

\subsection{Structure-Phase State of The Surface Layer Formed As A Result of Multicyclic Fatigue Tests of Steel Processed By an Electron Beam}

As mentioned above, the electron-beam processing of 08Cr18Ni10Ti steel is accompanied by formation of a structure of cellular crystallization in the surface layer. Fatigue loading of steel did not result in failure of the given structure. Crystallization cells have an equiaxed form with the average sizes of cells $\mathrm{D}=368.4 \mathrm{~nm}$ that is slightly more than the sizes of steel cells irradiated by electron beam. In the cells volume of crystallization the chaotically distributed dislocations with scalar density of $1.7 \times 10^{10} \mathrm{~cm}^{-2}$ are observed. Along the cell boundaries the titanium carbide particles of $\mathrm{TiC}$ composition and particles of $\mathrm{Cr}_{15} \mathrm{Fe}_{9}$ compound are located. Particles have a round form, the average sizes of particles are $50 \mathrm{~nm}$ that is $\sim 2.8$ times larger than the average particle sizes before fatigue tests. Microtwins in crystallization cells are not revealed.

The layer with structure of cellular crystallization is located next to the layer with polycrystalline structure. In the grain volume the microtwins of deformation origin and dislocation substructure are observed.

If before the deformation there was a dislocation substructure in the form of chaos and nets in the grains, then after failure - along with the chaos and nets, the dislocation bundles, broken subboundaries and dislocation cells of various degree of perfection are revealed. The average cell sizes are $294.2 \pm 75 \mathrm{~nm}$. Farther and farther from the face of the sample the quantity of dislocation substructures decreases rapidly. In the layer, located at the depth of $10 \mu \mathrm{m}$, there are only cells and nets; at the depth of $80 \mu \mathrm{m}$ - grids. The diagram of dislocation substructures being formed in the failure zone of $08 \mathrm{Cr} 18 \mathrm{Ni10 \textrm {Ti }}$ steel, subjected to electron-beam processing and the subsequent fatigue loading, is given in fig. 2 .

The performed layer-by-layer investigations of the 
defective substructure make it possible to carry out the analysis of the steel structure gradient, formed as a result of fatigue loading before failure.

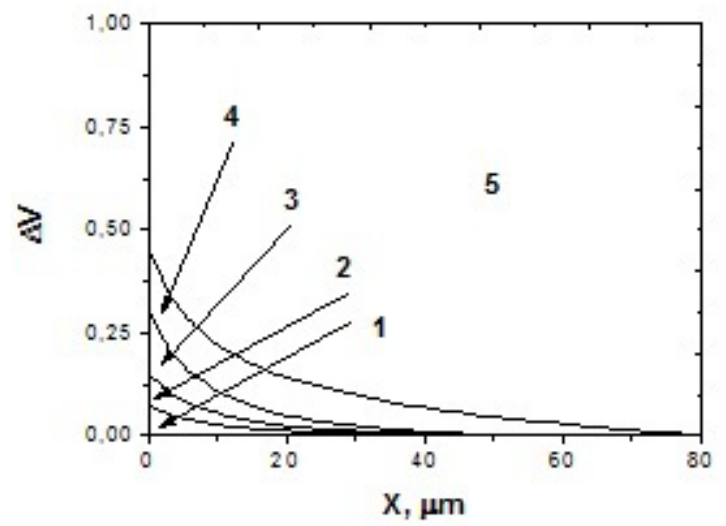

Figure 2. Diagram of dislocation substructures formed in the destruction zone of $08 \mathrm{Cr} 18 \mathrm{Ni10Ti}$ steel subjected to electron beam processing $\left(\mathrm{E}_{\mathrm{S}}=25\right.$ $\mathrm{J} / \mathrm{cm}^{2}$ ) and to the subsequent fatigue loading; 1 - the broken subboundaries, 2 - bundles; 3 - chaos; 4 - cells; 5 - grids

The electron-beam processing and the subsequent fatigue loading of the steel results in formation of internal stress fields in the material which are shown in the form of bend extinction contours. The main parameters of bend extinction contours, defined by the electron microscope images of steel structure, are the contour width and density (number of contours in one unit of the image area). The first parameter is connected with size of the internal stress fields; the second one characterizes the number of sources of stress fields formed in steel.
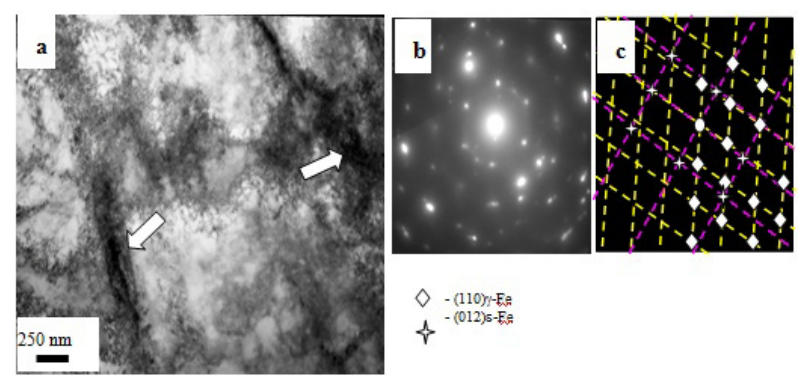

Figure 3. The structure formed in the surface layer of $08 \mathrm{Cr} 18 \mathrm{Ni} 10 \mathrm{Ti}$ steel processed by an electron beam and destroyed as a result of fatigue tests; a bright-field image; $\mathrm{b}$ - micro-electron-diffraction pattern; $\mathrm{c}$ - indexing scheme of micro-electron-diffraction pattern. The arrow in (a) points at the $\varepsilon$-phase crystals

In the material under investigation the layer characterized by the higher concentration of sources of internal stress fields with relatively high level of their amplitude is formed at the depth of $\sim 10 \mu \mathrm{m}$.

All these factors, obviously, indicate that as a result of the processes in the steel surface layer (layer thickness is $\sim 80$ $\mu \mathrm{m})$ the formation and coagulation of titanium carbide particles located in the grain volume of $\gamma$-phase take place.

The microdiffraction analysis of the layer structure of steel surface revealed some transformations caused by iron polymorphism in the process of fatigue loadings. Namely, in the foil next to the face of the failed sample the additional reflexes belonging to $\varepsilon$-phase (fig. 3) are found on micro-electron-diffraction patterns.

Additional reflexes belonging to $\varepsilon$-phase and $\alpha$-phase are found in the micro-electron-diffraction pattern at the depth of $\sim 10 \mu \mathrm{m}$. At the depth of $\sim 80 \mu \mathrm{m}$ additional reflexes belonging only to $\alpha$-phase (fig. 4 ) are found.
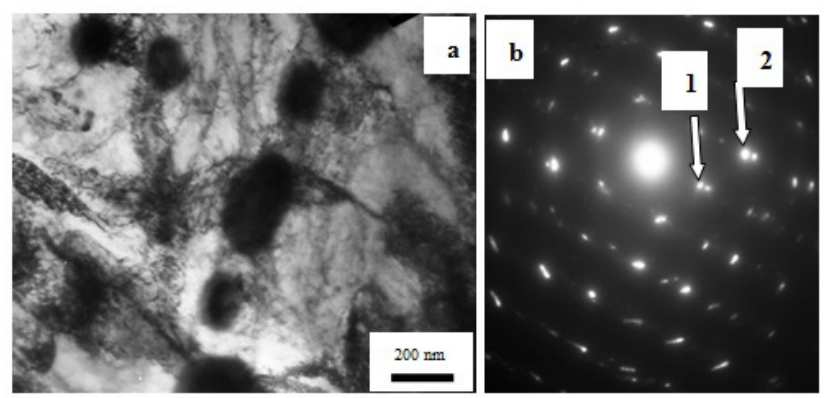

Figure 4. The structure formed at the depth of $\sim 80 \mu \mathrm{m}$ in $08 \mathrm{Cr} 18 \mathrm{Ni1} 10 \mathrm{Ti}$ steel, processed by an electron beam and destroyed in the result of fatigue tests; $\mathrm{a}$ - bright-field image; $\mathrm{b}$ - micro-electron-diffraction pattern. Arrows in (b) point at reflexes of $\alpha$-phase: 1 -[110]; 2 -[112]

As a rule, formation of $\varepsilon$ - and $\alpha$-phases results in the stress of high level in the volumes of $\gamma$-matrix adjoining them. Analysis of the material structure by the method of thin foils in the areas containing crystals $\varepsilon$ - and $\alpha$-phases crystals reveals a considerable quantity of bend extinction contours pointing either at the bend-torsion of a foil (fig. 3), or etching along the boundary between the two phases (fig. 4).

\section{Conclusions}

Electron-beam processing of the sample surfaces of $08 \mathrm{Cr} 18 \mathrm{Ni10Ti}$ steel is carried out and multicyclic fatigue tests are conducted. The fatigue durability increase by the factor of 3.44 of the modified by electron beam steel 08Cr18Ni10Ti (in comparison with the non-irradiated material) is revealed. It is shown that multicyclic fatigue tests of $08 \mathrm{Cr} 18 \mathrm{Ni10Ti}$ steel, subjected to the preliminary electron-beam processing, are accompanied by the formatio $\mathrm{n}$ of a gradient structure. It is determined that one of the reasons of fatigue durability increase of the irradiated steel is a grain and subgrain structure refinement, particle dissolution of carbide phase in the surface layer initiated by the electron-beam processing. It is shown that the destruction of $08 \mathrm{Cr} 18 \mathrm{Ni} 10 \mathrm{Ti}$ steel processed by an electron beam in the result of multicyclic fatigue tests can be a consequence of $\varepsilon$ - and $\alpha$-phases formation. Along their interface with $\gamma$-phase the formation of stress fields of high level, relaxing via microcracks generation is observed.

\section{ACKNOWLEDGEMENTS}

The authors would like to gratefully acknowledge the support of MES of Russia (Contract No. 02.740.11.0538). 


\section{REFERENCES}

[1] A. Sarkar, A. Bhowmik, S. Suwas, "Microstructural characterization of ultrafine-grain interstitial- free steel by X-ray diffraction line profile analysis”, Appl. Phys. A, vol. 94, no. 4, pp. 943-948, 2009.

[2] M. Gerland, J. P. Dufour, L. Fouilland-Paillé, P. Violan, H. N. Presles, "Fatigue behaviour in a plastic strain-controlled mode of an austenitic stainless steel treated by explosive", American Journal of Materials Science, vol. 31, no. 8, pp. 2071-2080, 1996.

[3] O.V. Sosnina, A.V. Gromov, E.Yu. Suchkova, E.V. Kozlov, Yu.F. Ivanov, V.E. Gromov, "The structural-phase state changes under the pulse cur-rent influence on the fatigue loaded steel", International Journal of Fatigue, vol. 27, no. 10-12, pp. 1221-1226, 2005.

[4] O.V. Sosnin, A.V. Gromova, Yu.F. Ivanov, "Control of austenite steel fatigue strength", International Journal of Fatigue, no. 10-12, pp. 1186-1191, 2005.

[5] S.V. Konovalov, A.A. Atroshkina, Yu.F. Ivanov, V.E. Gromov, "Evolution of dislocation substructures in fatigue loaded and failed stainless steel with the intermediate electropulsing treatment", Materials Science and Engineering A, vol. 527, no. 12, pp. 3040-3043, 2010.
[6] Hong W., Wang D.Z., Yang W.D., "High cycle fatigue life improvement of polycrystalline alpha Iron modified by silver, chromium, aluminium and ittrium ion implantation", Scripta Metallurgica et Materialia, vol.32, no. 12, pp. 2001-2007, 1995.

[7] V.P. Rotshtein, D.I. Proskurovsky, G.E. Ozur, Y.F. Ivanov, A.B. Markov, "Surface Modification and alloying of metallic materials with low energy high current electron beams", Surface and Coating Technology, vol. 180-181, pp. 377-381, 2004.

[8] V.P. Rotshtein, D.I. Proskurovsky, G.E. Ozur, K.V. Karlik, Y.F. Ivanov, A.B. Markov, "Microstructure of near surface layers of austenic stainless steels irradiated with low energy high current electron beams", Surface and Coating Technology, vol. 180-181, pp. 382-386, 2004.

[9] P.B. Hirsch, A. Howie, R.B. Nicholson, "Electron Microscopy of Thin Crystals", Krieger Publishing Co., Melbourne, 1977.

[10] E.V. Kozlov, A.N. Zhdanov, N.A. Popova, "Subgrain structure and internal stress field in UFG materials: problem of Hall-Petch ation", Materials Science and Engineering A, vol. 387-389, pp. 789-794, 2007.

[11] E.V. Kozlov, A.N. Zhdanov, L.N. Ignatenco, Y.T. Zhu, T.G. Langdon, R.S. Mishra, Ultrafine Grained Materials II, Proc. of TMS Annual Meeting, Washington, pp. 419-428, 2002. 